\title{
Effect of pantoprazole on human gastric adenocarcinoma SGC7901 cells through regulation of phospho-LRP6 expression in Wnt/ $\beta$-catenin signaling
}

\author{
WEIDONG SHEN $^{1}$, XIAOPING ZOU ${ }^{2}$, MIN CHEN $^{2}$, YONGHUA SHEN ${ }^{2}$, \\ SHULING HUANG ${ }^{2}$, HUIMIN GUO ${ }^{2}$, LILI ZHANG ${ }^{2}$ and PENGFEI LIU ${ }^{1}$ \\ ${ }^{1}$ Department of Digestive Disease, Gastrointestinal Center, Jiangyin People's Hospital, Medical School \\ of the University of Southeast China, Jiangyin, Jiangsu 214400; ${ }^{2}$ Department of Gastroenterology, \\ Nanjing Drum Tower Hospital, Clinical College of Traditional Chinese and Western Medicine, \\ Nanjing University of Chinese Medicine, Nanjing, Jiangsu 210008, P.R. China
}

Received February 17, 2013; Accepted April 23, 2013

DOI: $10.3892 /$ or.2013.2524

\begin{abstract}
Recent studies have found that an acidic tumor microenvironment is the key to managing cancer progression and metastasis. Our previous study found that proton pump inhibitors (PPIs) inhibit the expression of vacuolar-ATPases (V-ATPases) and reverse the transmembrane $\mathrm{pH}$ gradient. The present study was conducted to explore the effect of pantoprazole on gastric adenocarcinoma through the regulation of Wnt/ $\beta$-catenin signaling. We used SGC7901 human gastric cancer cells as an in vitro model to study the effect of pantoprazole. The antiproliferative, pro-apoptotic and anti-invasive effects of pantoprazole were examined. The effects of pantoprazole on the expression of the Wnt/ $\beta$-catenin signaling pathway were also studied by western blotting. Our study found that pantoprazole inhibited the proliferation and induced the apoptosis of SGC7901 human gastric cancer cells. The expression of V-ATPases was decreased following treatment with pantoprazole. Further study found that pantoprazole treatment caused a decrease in phospho-LRP6, but not in LRP6. $\beta$-catenin in $\mathrm{Wnt} / \beta$-catenin signaling and its target genes c-Myc and cyclin D1 were also decreased upon the inhibition of V-ATPases. Therefore, pantoprazole could be characterized as a V-ATPase inhibitor for treating gastric cancer by inhibiting the phosphorylation of LRP6 in Wnt/ $\beta$ catenin signaling.
\end{abstract}

Correspondence to: Dr Pengfei Liu, Department of Digestive Disease, Gastrointestinal Center, Jiangyin People's Hospital, Medical School of the University of Southeast China, Shoushan Road 163, Jiangyin, Jiangsu 214400, P.R. China

E-mail: shenwd2003@yahoo.com.cn

Key words: vacuolar-ATPases, pantoprazole, gastric cancer, $\mathrm{Wnt} / \beta$-catenin, signaling

\section{Introduction}

Gastric cancer is the leading cause of cancer-related mortality in China and is the third leading cause of cancer-related mortality in North America and Western Europe (1). Previous studies have found that an acidic tumor microenvironment is key to managing cancer progression and metastasis (2-4). Vacuolar-ATPases (V-ATPases), specific proton pumps of the cell, have an important role in maintaining a relatively neutral intracellular $\mathrm{pH}(\mathrm{pHi})$, an acidic luminal $\mathrm{pH}$, and an acidic extracellular $\mathrm{pH}(\mathrm{pHe})$. They are overexpressed in many types of metastatic cancers and are positively correlated with invasive and metastatic tumor potential (5). Furthermore, blocking the expression of V-ATPases can inhibit the growth and metastasis of human cancer (6).

Some molecules and drugs that inhibit V-ATPases have been identified (7), such as bafilomycin, concanamycin and NiK-12192, but their toxic effect and poor results in preclinical tests have limited their development as therapeutic agents. Recent insight into the mechanism of tumor acidification has provided new strategies for targeting V-ATPases (8). Proton pump inhibitors (PPIs) could represent a class of drugs suitable to this purpose (9). PPIs have demonstrated gastric acid suppression and have been applied in acid-related diseases generally with good safety and few side effects. A specific target of PPIs is $\mathrm{K}^{+} / \mathrm{H}^{+}$-ATPase which is located in gastric parietal cells. Moreover, our previous study found that PPIs can inhibit the expression of V-ATPases, and reverse the transmembrane $\mathrm{pH}$ gradient (10).

Among the cancer-related signaling pathways, the canonical Wnt pathway, also known as the Wnt/ $\beta$-catenin pathway, is involved in gastrointestinal carcinogenesis. Wnt ligands engage their receptor complex, stabilize intracellular levels of $\beta$-catenin, and allow the nuclear accumulation of $\beta$-catenin, together with the transcription factor lymphoid enhancer-binding factor $1 / \mathrm{T}$ cell-specific factor, followed by transcriptional activation of Wnt/ $\beta$-catenin target genes such as c-Myc and cyclin D1 (11). In this study, we explored the effect of a PPI on gastric carcinoma by regulating $\mathrm{Wnt} / \beta$-catenin signaling. 


\section{Materials and methods}

Drugs. Pantoprazole was purchased from Altana Pharma (Konstanz, Germany; AGD-78467). According to our previous study, a concentration $>20 \mathrm{mg} / \mathrm{ml}$ of pantoprazole inhibited the proliferation of SGC7901 cells. Pantoprazole was resuspended in normal saline at $20 \mathrm{mg} / \mathrm{ml}$ immediately before use.

Cell line and cell culture. The human gastric adenocarcinoma cell line, SGC7901, was kindly provided by the Department of Oncology, Drum Tower Hospital of the Nanjing University Medical School. Cells were cultured in RPMI-1640 (HyClone, Logan, UT, USA) supplemented with $10 \%$ fetal bovine serum (FBS) (Hangzhou Sijiqing Biological Engineering Materials, China) and antibiotics (100 U/ml penicillin and $100 \mu \mathrm{g} / \mathrm{ml}$ streptomycin) in humidified air with a $5 \% \mathrm{CO}_{2}$ atmosphere at $37^{\circ} \mathrm{C}$ (Direct Heat $\mathrm{CO}_{2}$ incubator; Thermo Scientific, Rockford, IL, USA).

Transfection. Cells plated in 100-mm dishes were transfected at $50-80 \%$ confluence with V-ATPase expression vectors or with control vectors, using the liposome-mediated transfection method. SGC7901 cells were transfected with an shRNA-V-ATPase or negative control vector (GAPDH) for 2 days, then trypsinized and plated at low density. Stable clones were selected by maintaining cells in medium containing G418 antibiotic.

Cell viability assay. The cytotoxicity of pantoprazole was determined using the MTT (KeyGen Biotech Co., Ltd., China) assay. Cells $\left(1 \times 10^{4} /\right.$ well $)$ were plated in 96 -well plates in $200 \mu \mathrm{l}$ of medium/well and then treated with pantoprazole at $20 \mathrm{mg} / \mathrm{ml}$. Control cells were treated with Dulbecco's modified Eagle's medium (DMEM). At different time points, $50 \mu 1$ of $5 \mathrm{mg} / \mathrm{ml}$ MTT was added, and the cells were cultured for another $4 \mathrm{~h}$. The supernatant was removed, and $150 \mu \mathrm{l}$ of dimethyl sulfoxide (DMSO) was added per well. The absorbance at $570 \mathrm{~nm}$ was measured with a microplate reader (Tecan Sunrise, Switzerland), using wells without cells as blanks and untreated cells as a negative control. The viability of the drug-treated cells was expressed as a percentage of the population growth with standard error of the mean relative to that of the untreated control cells.

Annexin V-fluorescein isothiocyanate (FITC) apoptosis detection. Apoptosis detection in cells was performed by the Annexin V-FITC and propidium iodide (PI) double staining apoptosis detection kit (KeyGen Biotech, Co. Ltd.) using flow cytometry (BD Biosciences, Franklin Lakes, NJ, USA). Briefly, the cells were trypsinized, washed with phosphate-buffered saline (PBS), centrifuged and resuspended with Annexin V binding buffer $(500 \mu 1)$. The cells were incubated with $5 \mathrm{ml}$ Annexin V-FITC solution for $5 \mathrm{~min}$ at room temperature. In the same step, PI was added at $5 \mu \mathrm{g} / \mathrm{ml}(5 \mu \mathrm{l})$ for another 5 min to distinguish necrotic cells. The samples were analyzed within $1 \mathrm{~h}$ by fluorescence-activated cell sorter (FACS) with CellQuest software (version 3.3).

Colony formation assay. Cells $\left(6 \times 10^{4} /\right.$ well) were plated in Petri dishes with a $6-\mathrm{cm}$ diameter with $10 \mathrm{ml}$ of DMEM
(Gibco-BRL, Carlsbad, CA, USA) containing 10\% fetal calf serum (FCS) (HyClone) in the presence or absence of various concentrations of pantoprazole at $37^{\circ} \mathrm{C}$. After culture for 10 days, colonies consisting of $>50$ cells were counted under the microscope.

Matrigel invasion assay. For the invasion assay, a modified Boyden chamber (Neuro Probe, Gaithersburg, MD, USA) was used. The pore size of the polycarbonate filters was $8.0 \mu \mathrm{m}$. The bottom chamber of the Transwell chamber was filled with $30 \mu$ l RPMI-1640 containing 10\% FBS. The cells were then suspended at a density of $1 \times 10^{5}$ cells $/ \mathrm{ml}$ in $500 \mu 1$ of RPMI supplemented with $0.5 \%$ FBS and pantoprazole, and added to $8-\mu \mathrm{m}$ porous BioCoat Matrigel chamber inserts (BD Biosciences) and placed in wells filled with $0.7 \mathrm{ml}$ of medium supplemented with $10 \%$ FCS as a chemoattractant. After 2 days of incubation, the upper side of the filter was scraped with a cotton tip to eliminate cells that had not migrated through it. To obtain the total apoptosis rate and inhibition rate by pantoprazole for $48 \mathrm{~h}$, we calculated the number of cells which did not undergo apoptosis (Live cells $=$ plated cells + proliferated cells - apoptotic cells). The invasive ability of the cells was determined by counting the cells that had migrated to the lower side of the filter with a microscope. The relative invasion rate was obtained using the following formula: Relative invasion rate $=$ migrated cells/live cells. Experiments were performed in triplicate, and at least 10 fields were counted for each experiment.

Western blot analysis. Proteins were extracted in lysis buffer $(30 \mathrm{mmol} / \mathrm{l}$ Tris, $\mathrm{pH}$ 7.5, $150 \mathrm{mmol} / \mathrm{l}$ sodium chloride, $1 \mathrm{mmol} / \mathrm{l}$ phenylmethylsulfonyl fluoride, $1 \mathrm{mmol} / 1$ sodium orthovanadate, $1 \%$ Nonidet P-40, $10 \%$ glycerol and phosphatase and protease inhibitors). The proteins were then separated by SDS-PAGE and electrophoretically transferred onto polyvinylidene fluoride membranes. The membranes were probed with antibodies overnight at $4^{\circ} \mathrm{C}$, and then incubated with the secondary antibody. Images of the western blotting products were captured and analyzed by Quantity One v4.31 (Bio-Rad, Hercules, CA, USA).

Data analysis. Statistical comparisons were performed with the software package SPSS 13.0 using the Student's t-test for paired observations or one-way ANOVA with SNK, LSD and Dunnett's methods. All data are presented as means \pm standard deviation (SD). $\mathrm{P}<0.05$ was considered statistically significant. Mean values and SD were calculated for experiments carried out in triplicate.

\section{Results}

Growth inhibition of human SGC7901 cells by pantoprazole. The inhibitory activity of pantoprazole on the proliferation of human gastric cancer SGC7901 cells was investigated. Cells were grown in the absence or presence of pantoprazole $(20 \mathrm{mg} / \mathrm{ml})$ for 12,24 and $48 \mathrm{~h}$. MTT assays were then performed. The growth inhibition occurred in a time-dependent manner. The cell viability of SGC7901 cells in the PPI group $(43.1 \pm 3.9 \%)$ was lower than that in the shRNA-GAPDH group $(89 \pm 4.9 \%)$ at $48 \mathrm{~h}$ post treatment (Fig. 1A). The effect 
$\mathbf{A}$

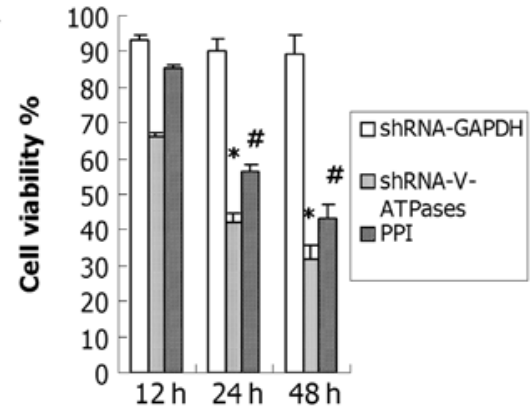

B

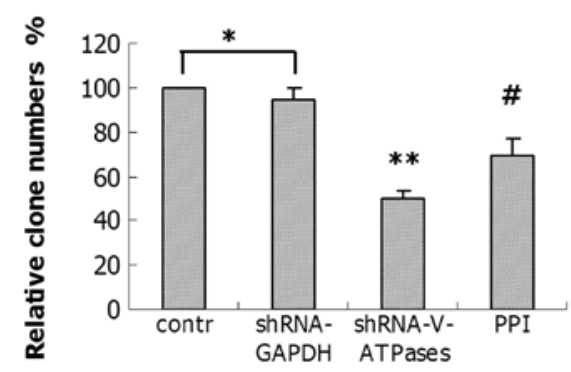

Figure 1. Pantoprazole suppresses the growth of SGC7901 cells. (A) Comparison of the cell viability of SGC7901 cells after being transfected with shRNA-GAPDH or shRNA-V-ATPases after 12, 24 and $48 \mathrm{~h}$. SGC7901 cells were treated with pantoprazole $(20 \mathrm{mg} / \mathrm{ml})$ for 12,24 and $48 \mathrm{~h}$. Growth inhibition was determined by the MTT assay. (B) Colony formation assay. Cell colonies were counted after staining with crystal violet and are shown in the graph. The bars in the graph represent the means \pm SD. Experiments were performed in triplicate.

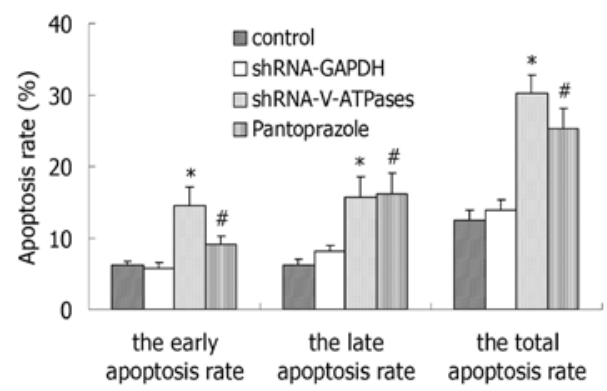

Figure 2. Comparison of the apoptosis rate of SGC7901 cells after treatment with pantoprazole. ${ }^{*, \#} \mathrm{P}<0.05$, indicating that the apoptosis rate was significantly higher than that in the control group.

of pantoprazole on colony formation of the cells was also assessed. On day 10 post-treatment, pantoprazole suppressed the colony formation of the cells (Fig. 1B). These results suggest that pantoprazole preferentially inhibits the growth of SGC7901 cells.

Apoptosis detection. A quantitative analysis of the fluorescent signals was performed by FACS. As noted in Fig. 2, the total apoptosis was increased from $10.5 \%$ in the control cells and reached $25.3 \%$ following treatment with $20 \mathrm{mg} / \mathrm{ml}$ pantoprazole at $48 \mathrm{~h}$. Treatment of SGC7901 cells showed a similar dose-dependent response pattern for the early and late apoptosis rates (Fig. 2).

Matrigel cell invasion assay. We observed a significant difference between SGC7901 cells with and without pantoprazole
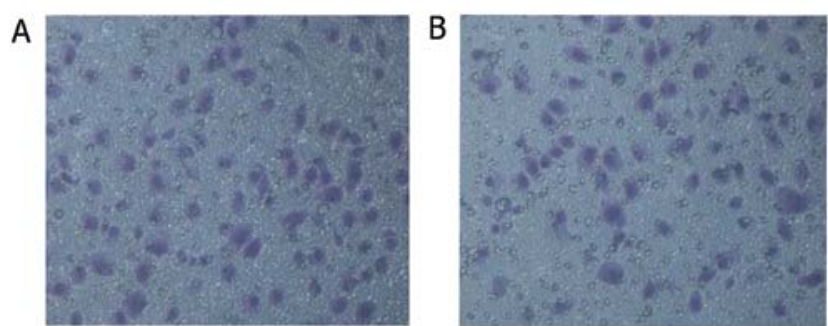

C
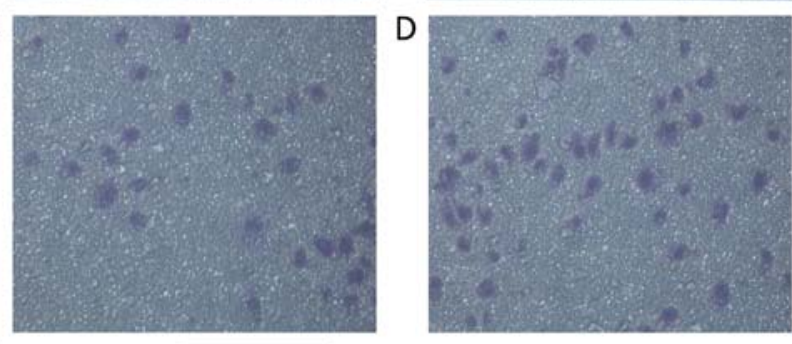

$\mathrm{E}$

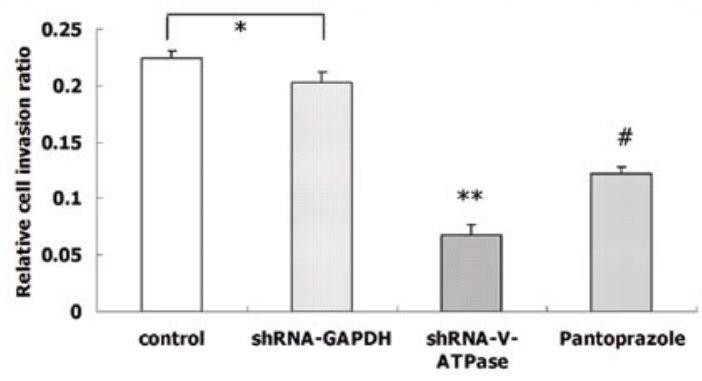

Figure 3. Effects of pantoprazole on the invasion of gastric cancer cells. Cell invasion $48 \mathrm{~h}$ after treatment with pantoprazole was evaluated in the Matrigel invasion assay as described in 'Materials and methods'. (A-D) Representative microscope images after pantoprazole treatment (magnification, x200). (A) Control without pantoprazole; (B) shRNA-GAPDH group; (C) shRNAV-ATPase group; (D) $20 \mathrm{mg} / \mathrm{ml}$ pantoprazole group. (E) Comparison of the rate of SGC7901 cell invasion. Data are expressed as percent change (means $\pm \mathrm{SD}$ ) and represent three independent experiments. $\left({ }^{* *}, \mathrm{P}<0.05\right.$ vs control; ${ }^{*} \mathrm{P}>0.05$ vs. control; one-way analysis of variance (ANOVA) followed by Tukey's multiple comparison).

treatment in the migration assay. Moreover, SGC7901 cell invasion was reduced by pantoprazole at $20 \mathrm{mg} / \mathrm{ml}(\mathrm{P}<0.05)$ in the Matrigel invasion assay (Fig. 3).

Effects of pantoprazole on V-ATPases. To determine whether pantoprazole inhibits the expression of V-ATPases, SGC7901 cells were treated with $20 \mathrm{mg} / \mathrm{ml}$ pantoprazole and after $48 \mathrm{~h}$ were assessed for the presence of V-ATPase expression by immunofluorescence and western blotting.

After $48 \mathrm{~h}$ of pantoprazole treatment, the expression of V-ATPases was altered when compared with that in the control group (Fig. 4). The expression of V-ATPases in the pantoprazole group was significantly less than that in the control group $(\mathrm{P}<0.05)$, whereas no significant difference was found between the control group and the shRNA-GAPDH group.

Effects on LRP6 and downstream genes by pantoprazole. Research has demonstrated that phosphorylation of LRP6 (which correlates with LRP6 activation) requires V-ATPase activity, suggesting that the receptor may need to enter an acidic intracellular compartment to become phosphorylated. We tested whether pantoprazole inhibits the expression of phospho-LRP6 and its downstream gene, $\beta$-catenin. The expression levels of these proteins in SGC7901 cells treated 

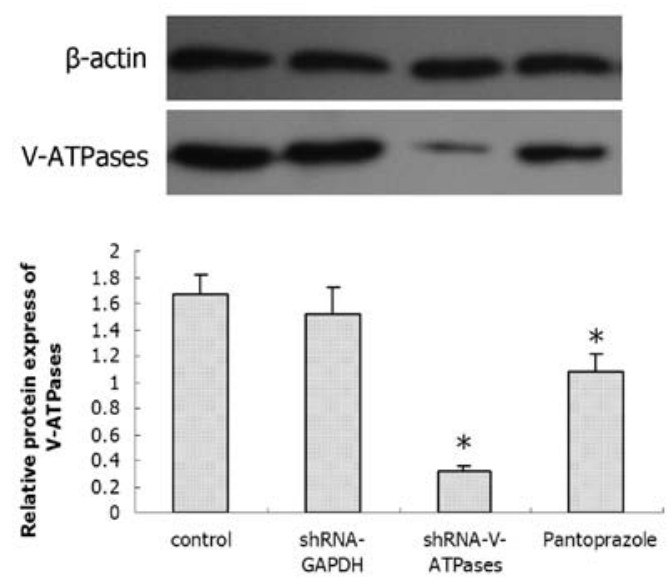

Figure 4. V-ATPase protein detection by western blot analysis. Effects of pantoprazole treatment on V-ATPase expression in SGC7901 cells at $48 \mathrm{~h}$. ${ }^{*} \mathrm{P}<0.05$, significant difference when compared with the control group.

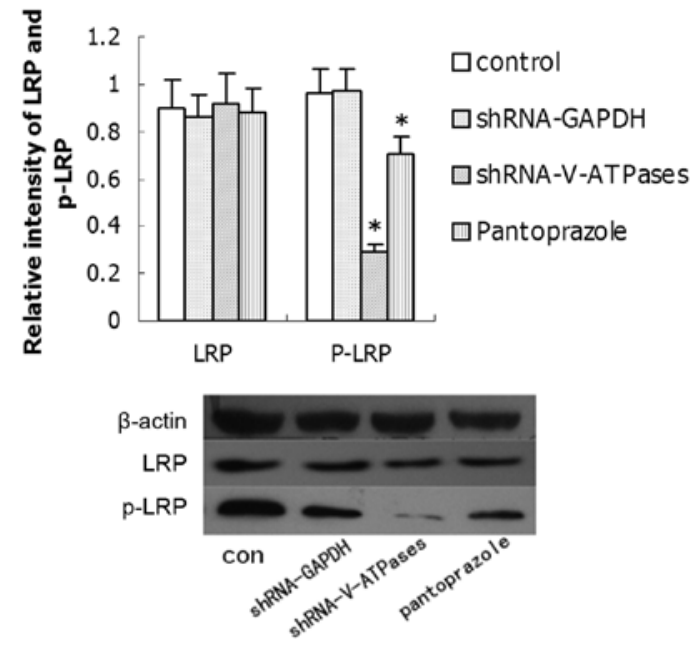

Figure 5. Expression of LRP6 and p-LRP6 following pantoprazole treatment for $48 \mathrm{~h}$. Cytosolic and nuclear proteins were prepared and used in western blotting experiments; $\beta$-actin was used as a loading control. Results are presented as the means \pm SD. Experiments were performed in triplicate.

with $20 \mathrm{mg} / \mathrm{ml}$ pantoprazole after $48 \mathrm{~h}$ were detected by western blotting (Fig. 5). The expression of phospho-LRP6 and $\beta$-catenin was weak in the SGC7901 cells after pantoprazole treatment compared with that in the control group, but LRP6 showed no difference.

To examine the relationship between inhibition of $\mathrm{V}$-ATPases and $\mathrm{Wnt} / \beta$-catenin signaling in gastric cancers, we also detected expression of c-Myc and cyclin D1, which are well-known target genes of the Wnt $/ \beta$-catenin canonical pathway. c-Myc and cyclin D1 were markedly downregulated in SGC7901 cells after treatment with $20 \mathrm{mg} / \mathrm{ml}$ pantoprazole (Fig. 6). Therefore, we confirmed that the inhibition of V-ATPase by pantoprazole reduced the expression of c-Myc and cyclin D1.

\section{Discussion}

The V-ATPase is a multiprotein complex localized in intracellular organelles and at the plasma membrane. It is involved

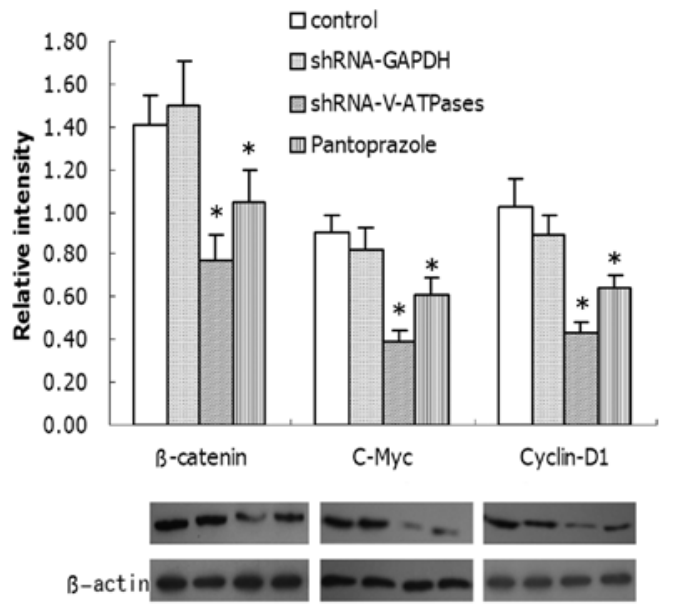

Figure 6. The protein expression of $\beta$-catenin, c-Myc and cyclin D1 in SGC7901 cells treated with $20 \mathrm{mg} / \mathrm{ml}$ pantoprazole was significantly downregulated. ${ }^{*} \mathrm{P}<0.05$, compared with that in the control group.

in diverse processes such as phagocytosis, virus entry, metastasis, and embryonic left-right patterning. Its main mechanism is to pump protons and acidify vesicles, thereby promoting vesicular traffic, notably endocytosis $(12,13)$. V-ATPases exist in various cell types, including those of many solid tumors, and are involved in progression and metastasis. These enzymes contribute to the acidic $\mathrm{pH}$ of solid tumors, and have been proposed as a therapeutic target for selective anticancer treatments $(8,14,15)$ In recent years, several studies have shown that PPIs such as omeprazole, esomeprazole and pantoprazole have an antineoplastic activity against human hematopoietic and solid tumors (16-18). Our previous study also found that pantoprazole reversed the transmembrane $\mathrm{pH}$ gradient and chemosensitized SGC7901 cells to antitumor agents (10). These results suggest that PPIs may be useful as an anticancer agent. However, to date, no precise molecular mode of action in cancer cells has been presented. Thus, we further studied its possible cell targets.

Our previous study (10) found that pantoprazole inhibits the expression of V-ATPases at concentrations of $20 \mathrm{mg} / \mathrm{ml}$, and inhibits the concentration of V-ATPases around the cell membrane, affecting its role in transporting $\mathrm{H}^{+}$out of the cell, and thereby decreasing the intracellular $\mathrm{pH}$ and increasing the extracellular $\mathrm{pH}$ value. Thus, in the present study, the concentration we applied was $20 \mathrm{mg} / \mathrm{ml}$. We found that pantoprazole inhibited the proliferation, induced apoptosis, and decreased the invasive ability of cells. Thus, we confirmed that V-ATPase is a target of pantoprazole in SGC7901 cells and that pantoprazole is a V-ATPase inhibitor. To date, a few V-ATPase inhibitors have been identified, but none have been used clinically because of their toxic effect on normal cells (19-23). PPIs can suppress gastric acid and treat diseases related with gastric acid with few side effects. Therefore, we believe that PPIs, as anticancer agents, may potentially benefit many patient groups.

The Wnt pathway is known to be involved in the tumorigenesis of many human cancers, including colon cancer, breast cancer, lung cancer, melanomas and hepatocellular carcinoma (24-26). Dysregulation of this pathway can be caused by mutations in many molecular components (e.g., CTNNB1, 
AXIN or FZD7) in colon cancers, hepatocellular carcinomas and other cancers (27-29). Recently, Cruciat et al (30) found that V-ATPase is involved in Wnt/ $\beta$-catenin signaling, which is related to tumor development and metastasis. LRP6 phosphorylation is accompanied by receptor internalization in caveolin-containing vesicles and endocytosis is essential for Wnt/ $\beta$-catenin signaling $(31,32)$. This raised the possibility that V-ATPases may influence LRP6 endocytosis, phosphorylation and $\beta$-catenin activation. Our study found that, consistent with the inhibition of V-ATPases by pantoprazole, phospho-LRP6 and $\beta$-catenin simultaneously decreased, but LRP6 was unchanged. To confirm that pantoprazole inhibits Wnt/ $\beta$-catenin signaling, we also detected c-Myc and cyclin D1, which are well-known target genes of the Wnt canonical pathway (33). c-Myc and cyclin D1 were markedly downregulated after treatment with pantoprazole at concentrations of $20 \mathrm{mg} / \mathrm{ml}$ in SGC7901 cells.

In conclusion, we report that pantoprazole as an inhibitor of V-ATPases can induce cell death in human gastric cancer using the Wnt/ $\beta$-catenin pathway as a mechanism. Although more careful analyses of the effects of pantoprazole on various organs remain to be carried out, the results of this study showed that V-ATPase is a potential cell target of pantoprazole for the chemotherapy of gastric cancers.

\section{Acknowledgements}

This study was supported by the National Science Foundation Grant (no. 81071816). Special thanks to Yong Liu and Junhao Chen for their technical assistance in the flow cytometry. We also thank Xingyun $\mathrm{Xu}$ for collecting the materials and references.

\section{References}

1. Parkin DM, Bray F, Ferlay J and Pisani P: Global cancer statistics, 2002. CA Cancer J Clin 55: 74-108, 2005.

2. Chiche J, Brahimi-Horn MC and Pouysségur J: Tumor hypoxia induces a metatloic shift causing acidosis: a common feature in cancer. J Cell Mol Med 14: 771-794, 2010.

3. Trédan O, Galmarini CM, Patel K and Tannock IF: Drug resistance and the solid tumor microenvironment. J Natl Cancer Inst 99: 1441-1454, 2007.

4. Subarsky P and Hill RP: The hypoxic tumour microenvironment and metastatic progression. Clin Exp Metastasis 20: 237-250, 2003.

5. Sennoune SR, Bakunts K, Martinez GM, et al: Vacuolar $\mathrm{H}^{+}$-ATPase in human breast cancer cells with distinct metastatic potential: distribution and functional activity. Am J Physiol Cell Physiol 286: 1443-1452, 2004.

6. Lu X, Qin W, Li J, et al: The growth and metastasis of human hepatocellular carcinoma xenografts are inhibited by small interfering RNA targeting to the subunit ATP6L of proton pump. Cancer Res 65: 6843-6849, 2005.

7. Martinez-Zaguilan R, Lynch RM, Martinez GM and Gillies RJ: Vacuolar-type $\mathrm{H}(+)$-ATPases are functionally expressed in the plasma membranes of human tumor cells. Am J Physiol 265: C1015-C1029, 1993.

8. Fais S, De Milito A, You HY and Qin W: Targeting vacuolar $\mathrm{H}^{+}$-ATPases as a new strategy against cancer. Cancer Res 67: 10627-10630, 2007.

9. Barrison AF, Jarboe LA, Weinberg BM, et al: Patterns of proton pump inhibitor use in clinical practice. Am J Med 111: 469-473, 2011.

10. Chen M, Zou XP, Luo HS, et al: Effects and mechanisms of proton pump inhibitors as a novel chemosensitizer on human gastric adenocarcinoma (SGC7901) cells. Cell Biol Int 33 1008-1019, 2009.
11. Peifer $\mathrm{M}$ and Polakis P: Wnt signaling in oncogenesis and embryogenesis - a look outside the nucleus. Science 287: 1606-1609, 2000

12. Nishi T and Forgac M: The vacuolar (H+)-ATPases - nature's most versatile proton pumps. Nat Rev Mol Cell Biol 3: 94-103, 2002.

13. Swietach P, Vaughan-Jones RD and Harris AL: Regulation of tumor $\mathrm{pH}$ and the role of carbonic anhydrase 9. Cancer Metastasis Rev 26: 299-310, 2007.

14. Sennoune SR, Luo D and Martínez-Zaguilán R: Plasmalemmal vacuolar-type $\mathrm{H}^{+}$-ATPase in cancer biology. Cell Biochem Biophys 40: 185-206, 2004.

15. De Milito A, Canese R, Marino ML, et al: pH-dependent antitumor activity of proton pump inhibitors against human melanoma is mediated by inhibition of tumor acidity. Int $\mathbf{J}$ Cancer 127: 207-219, 2009.

16. Luciani F, Spada M, De Milito A, et al: Effect of proton pump inhibitor pretreatment on resistance of solid tumors to cytotoxic drugs. J Natl Cancer Inst 96: 1702-1713, 2004.

17. Yeo M, Kim DK, Kim YB, et al: Selective induction of apoptosis with proton pump inhibitor in gastric cancer cells. Clin Cancer Res 10: 8687-8696, 2004.

18. De Milito A, Iessi E, Logozzi M, et al: Proton pump inhibitors induce apoptosis of human B-cell tumors through a caspaseindependent mechanism involving reactive oxygen species. Cancer Res 67: 5408-5417, 2007.

19. Bowman EJ, Siebers A and Altendorf K: Bafilomycins: a class of inhibitors of membrane ATPases from microorganisms, animal cells, and plant cells. Proc Natl Acad Sci USA 85: 7972-7976, 1998.

20. Melikova MS, Blagoveshchenskaia AD, Nikol'skiǔ NN and Kornilova ES: Effect of an vacuolar proton pump inhibitor bafilomycin A1 on the intracellular processing of markers for receptor-mediated and liquid phase endocytosis. Tsitologiia 44: 807-816, 2002 (In Russian).

21. Petrangolini G, Supino R, Pratesi G, et al: Effect of a novel vacuolar- $\mathrm{H}^{+}$-ATPase inhibitor on cell and tumor response to camptothecins. J Pharmacol Exp Ther 318: 939-946, 2006.

22. Niikura K: Effect of a V-ATPase inhibitor, FR202126, in syngeneic mouse model of experimental bone metastasis. Cancer Chemother Pharmacol 60: 555-562, 2007.

23. Hesselink RW, Fedorov A, Hemminga MA and Prieto M: Membrane-bound peptides from V-ATPases subunit a do not interact with an indole-type inhibitor. J Pept Sci 14: 383-388, 2008.

24. Polakis P: Wnt signaling and cancer. Genes Dev 14: 1837-1851, 2000.

25. Korinek V, Barker N, Morin PJ, et al: Constitutive transcriptional activation by a $\beta$-catenin-Tcf complex in APC-/-colon carcinoma. Science 275: 1784-1787, 1997.

26. Rubinfeld B, Robbins P, El-Gamil M, et al: Stabilization of $\beta$-catenin by genetic defects in melanoma cell lines. Science 275 : 1790-1792, 1997.

27. Satoh S, Daigo Y, Furukawa Y, et al: AXIN1 mutations in hepatocellular carcinomas, and growth suppression in cancer cells by virus mediated transfer of AXIN1. Nat Genet 24: 245-250, 2002.

28. de La Coste A, Romagnolo B, Billuart P, et al: Somatic mutations of the $\beta$-catenin gene are frequent in mouse and human hepatocellular carcinomas. Proc Natl Acad Sci USA 95: 8847-8851, 1998.

29. Merle P, de la Monte S, Kim M, et al: Functional consequences of frizzled-7 receptor overexpression in human hepatocellular carcinoma. Gastroenterology 127: 1110-1122, 2004.

30. Cruciat CM, Ohkawara B, Acebron SP, et al: Requirement of prorenin receptor and vacuolar $\mathrm{H}^{+}$-ATPase-mediated acidification for Wnt signaling. Science 327: 459-463, 2010.

31. Blitzer JT and Nusse R: A critical role for endocytosis in Wnt signaling. BMC Cell Biol 7: 28, 2006.

32. Yamamoto $\mathrm{H}, \mathrm{Komekado} \mathrm{H}$ and Kikuchi $\mathrm{A}$ : Caveolin is necessary for Wnt-3a-dependent internalization of LRP6 and accumulation of $\beta$-catenin. Dev Cell 11: 213-223, 2006.

33. Wang J, Wang X, Gong W, et al: Increased expression of $\beta$-catenin, phosphorylated glycogen synthase kinase $3 \beta$, cyclin D1, and $c-m y c$ in laterally spreading colorectal tumors. J Histochem Cytochem 57: 363-371, 2009. 